\title{
Central Pars Plana Vitrectomy + Phacoemulsification + Intraocular Lens Implantation in Patients with Small Eyes, Cataract, and Narrow Anterior Chambers
}

\author{
Fermín Silva Cayatopa (D) \\ Ana Luisa González \\ Méndez (D) \\ Robinson Barrientos Ortiz (D) \\ Alejandro Silva Diaz \\ Fernando Godin Estrada (D) \\ Department of Ophthalmology, Research \\ Department Clínica La Luz, Lima, Peru
}

Correspondence: Ana Luisa González Méndez

Research Department Clínica La Luz, Department of Ophthalmology, Av.

Arequipa I 148, Lima, Peru

Tel +5I 947273992

Email dra.analuisagonzalez88@gmail.com
Purpose: To evaluate the results of central pars plana vitrectomy + phacoemulsification + intraocular lens implantation in patients with small eyes, cataract, and narrow chambers.

Methods: This prospective study was carried out in 89 eyes of 58 patients undergoing central pars plana vitrectomy + phacoemulsification + IOL implantation in small eyes with cataract at Clínica La Luz Eye Institute in Lima, Peru.

Results: The mean best corrected visual acuity (BCVA) was $0.8 \pm 0.6$ preoperatively, 0.5 \pm 0.6 at 1 month, $0.3 \pm 0.3$ at 6 months, $0.1 \pm 0.1$ at 9 months, and $0.05 \pm 0.1$ at 1 year, which was statistically significant from the preoperative period to 1 year of follow-up. Mean intraocular pressure was $22.09 \pm 2.4 \mathrm{mmHg}$ preoperatively, $14.55 \pm 2.9 \mathrm{mmHg}$ at 1 day, $12.94 \pm 2.04 \mathrm{mmHg}$ at 1 month, $12.01 \pm 1.2 \mathrm{mmHg}$ at 6 months, $12.20 \pm 1.9 \mathrm{mmHg}$ at 9 months, and $11.34 \pm 1.1 \mathrm{mmHg}$ at 1 year. The reduction in the intraocular pressure from the preoperative control period to the follow-up at 1 year was statistically significant. There was only one complication, a rupture of the posterior capsule, which was quickly resolved.

Conclusion: Central pars plana vitrectomy with phacoemulsification is a safe and effective technique to perform in narrow chambers with all types of cataracts, in experienced hands, which can avoid intraoperative complications.

Keywords: best corrected visual acuity, intraocular pressure, intraocular lens implantation, crowded anterior chamber

\section{Introduction}

Crowded anterior chamber (AC) is usually seen in eyes with small axial length. Small eye is a descriptive term for a group of disorders characterized by short axial length. ${ }^{1}$ Shallow AC with normal axial length occurs in some ocular conditions, such as anterior microphthalmos, ${ }^{2}$ intumescent cataracts, ${ }^{3}$ and angle closure glaucoma. ${ }^{4-6}$ In addition, systemic elevated blood pressure, chronic obstructive pulmonary disease, arteriosclerosis, obesity, and senility can cause AC shallowness and positive vitreous pressure during ophthalmic surgery. ${ }^{7}$

Narrow AC can cause difficulties in almost every step in phacoemulsification and intraocular lens (IOL) implantation surgery. From creation of the wound and capsulorhexis to the implantation of the $\mathrm{IOL}^{7}$ dealing with a narrow space inside the eye increases the incidence of complications such as capsulorhexis extension, Descemet's membrane detachment, corneal edema due to endothelial loss because of the contact of the phaco tip and the back of the cornea, and 
dialysis of the zonules. ${ }^{4,8}$ The elevated vitreous pressure in a narrow eye can result in prolapsed iris and rupture of the posterior capsule with vitreous loss, and may end with suprachoroidal hemorrhage. ${ }^{9}$ Postoperative complications, such as increased intraocular pressure (IOP), choroidal effusion, macular edema, and malignant glaucoma, occur frequently in such eyes. ${ }^{10}$ It was observed that the AC depth decreases by about $0.024 \mathrm{~mm}$ per year of age. ${ }^{11}$

The aim of this study was to evaluate the outcome of central pars plana vitrectomy during phacoemulsification and IOL implantation in eyes with shallow AC to prevent the associated complications.

\section{Methods}

This prospective study was carried out in 89 eyes of 58 patients diagnosed with cataract and narrow $\mathrm{AC}$ between 2020 and 2021 at Clínica La Luz Eye Institute in Lima, Peru.

All patients gave their written approval to the medical ethics committee of the Clinica La Luz research department for the use of the information from the clinical records, in accordance with the guidelines of the Declaration of Helsinki. The Medical Ethics Committee of the Clinica La Luz approved this study.

We included patients with cataract and narrow angle by gonioscopy, single eyes, and eyes with low endothelial count, and an ultrasound biometric was performed considering a small eye with an axial length of less than $22.0 \mathrm{~mm}$ and an AC depth of less than $2.0 \mathrm{~mm}$, with all types of cataract according to the LOCS III classification.

All patients underwent central pars plana vitrectomy plus phacoemulsification with IOL implantation, performed by the same surgeon.

Exclusion criteria were all patients who did not comply with the 12-month follow-up, and those with no light perception eyes, glaucoma, or age-related macular degeneration.

We evaluated the best corrected visual acuity (BCVA) using a Snellen card and converted to the logMAR scale. IOP was measured with a Goldman tonometer. BCVA was measured before the operation, and at 1 month, 6 months, 9 months, and 1 year after surgery. IOPs were followed preoperatively, and 1 day, 1 month, 6 months, 9 months, and 1 year after surgery. Intraoperative and postoperative complications were recorded.

\section{Surgical Technique}

All surgeries were performed by the same ophthalmologist, following aseptic and antiseptic procedures. A $3.5-\mathrm{mm}$ sclerotomy was performed posterior to the limbus with a selfsealing 23-gauge, one-port sclerotomy, without vitrectomizing. During the first few surgeries, we noticed that when the incisions were made simultaneously the eye was very soft. Thus, to avoid inadvertent touching of the anterior lens capsule, the incisions were no longer made simultaneously, and we began carrying out the main paracentesis with a keratome 2.2 ophthalmic blade. Topical anesthesia was applied. If a central pars plana vitrectomy was anticipated, a peribulbar and local anesthetic agent was administered. Trypan blue was immediately added, followed by washing with balanced salt solution (BSS), and additional viscoelastic material was placed through the paracentesis to deepen the AC. We used $2.3 \%$ sodium hyaluronate (Healon $5^{\circledR}$ ) or a soft-layer technique using 3.0\% sodium hyaluronate $-4.0 \%$ chondroitin sulfate $\left(\right.$ Viscoat $\left.^{\mathbb{R}}\right)$ followed by $1.0 \%$ sodium hyaluronate $\left(\right.$ Provisc $^{\circledR}$ ).

Immediately, a small amount of vitreous humor (approximately $0.2 \mathrm{~mL}$ ) was aspirated using an automated vitrectomy handpiece without infusion. A high vitrectomy cut-off rate $(2000 \mathrm{cfm})$ was used with a low vacuum setting $(150 \mathrm{mmHg})$ for approximately 10 seconds, with the tip of the vitrector pointing downwards to avoid breaking the posterior capsule, mainly in white cataracts that do not allow visualization of the vitrector. Continuous circular capsulorhexis and hydrodissection were performed, and phacoemulsification, using tilt-and-tumble and vertical phaco chop techniques in soft and hard cataracts, respectively. Then, a one-piece folding acrylic hydrophobic IOL was implanted. The surgery was performed through a temporary clear corneal incision (Figure 1A-D). (See Supplementary video S1 of the surgery.)

Limited anterior vitrectomy was performed using a phaco machine system with a 23-gauge, one-port, self-sealing sclerotomy. No more than $0.2 \mathrm{~mL}$ of vitreous humor was removed, so that the $\mathrm{AC}$ did not become too deep (Figure 1A-D). (See Supplementary video S1 of the surgery.)

\section{Postoperative Medication}

The patients were treated with topical antibiotic moxifloxacin $0.5 \% /$ dexamethasone $0.1 \%$ for 14 days. Topical steroid drops were administered every 4 hours for the first week and every 6 hours for the second week, and nepafenac $0.1 \%$ suspension was applied as an anti-inflammatory for 4 weeks after surgery. 

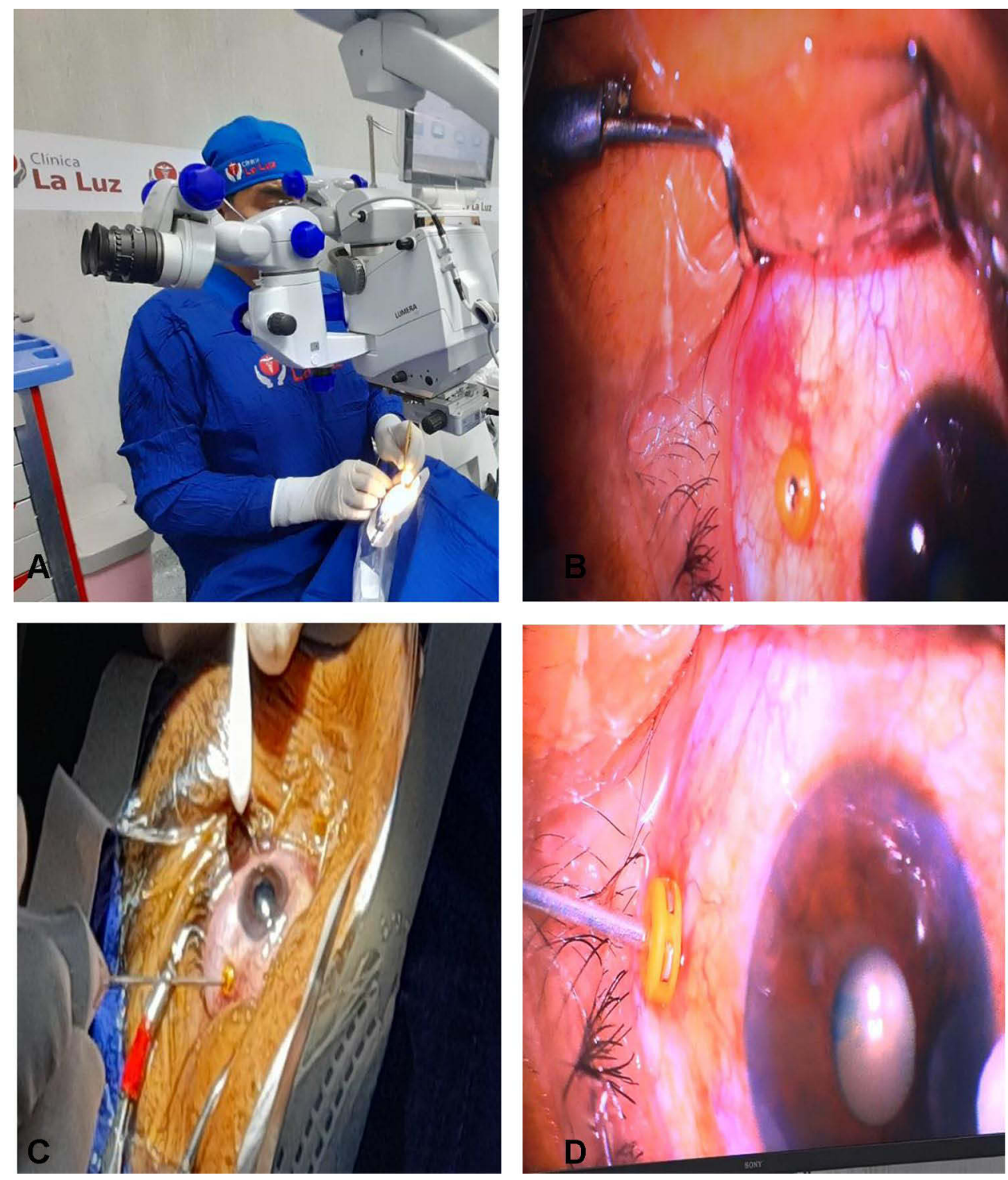

Figure I (A) The surgeon places the trocar using a swab to support the eye. (B) The placed trocar is visualized. (C) The vitrector of the Alcon Centurion ${ }^{\circledR}$ is introduced. (D) Posterior vitrectomy is performed for 10 seconds, counting the clock, with cuts of $2000 \mathrm{cfm}$, in a vacuum of $150 \mathrm{mmHg}$, with the vitrector tip pointing down so as not to touch the posterior capsule and to minimize the risk of hitting the retina.

\section{Statistical Analysis}

For the $\log M A R$ and IOP statistical comparison test, first, a global test called the Quade test was applied. When this test was significant, it was compared in pairs to locate the significance detected with the Quade test, using the pairwise test called "Pairwise comparisons using posthoc-Quade test". For the calculations, R version 4.0.5 (https://www.r-project.org) was used.

\section{Results}

Our study included 89 eyes of 58 patients with cataract and narrow angle, with axial length less than $22.0 \mathrm{~mm}$ and AC depth less than $2.0 \mathrm{~mm}$. The study group comprised 22 men $(37.9 \%)$ and 36 women $(62.1 \%)$, with a mean \pm SD age of $67.5 \pm 10.8$ years. All patients underwent central pars plana vitrectomy + phacoemulsification + IOL implantation. Demographic and clinical characteristics of the patients are described in Table 1.

\section{Visual Acuity}

The mean \pm SD BCVA preoperatively was $0.89 \pm 0.6$, and at 1 year postoperatively was $0.05 \pm 0.1$ (Table 2 and Figure 2). Visual acuity remained stable at 1 year of follow-up in $90.6 \%$ of the cases.

\section{IOP}

The mean \pm SD IOP preoperatively was $22.09 \pm 2.4 \mathrm{mmHg}$, and at 1 year postoperatively was $11.34 \pm 1.1 \mathrm{mmHg}$ 
Table I Demographic and Clinical Characteristics of Participants

\begin{tabular}{|l|c|}
\hline $\begin{array}{l}\text { Central Pars Plana Vitrectomy + } \\
\text { Phacoemulsification + IOL Implant }\end{array}$ & No. (\%) \\
\hline No. of patients & $58(100 \%)$ \\
\hline $\begin{array}{l}\text { Sex } \\
\text { Female } \\
\text { Male }\end{array}$ & $36(62.1 \%)$ \\
\hline $\begin{array}{l}\text { Age of patients (years) } \\
\text { Mean } \pm \text { SD }\end{array}$ & $22(37.9 \%)$ \\
\hline $\begin{array}{l}\text { No. of eyes } \\
\text { Right } \\
\text { Left }\end{array}$ & $67.5 \pm 10.8$ \\
\hline $\begin{array}{l}\text { Diagnosis } \\
\text { Small eye, cataract, and narrow chamber } \\
\text { Small eye, cataract, and narrow chamber + low } \\
\text { endothelial count }\end{array}$ & $89(100 \%)$ \\
\hline
\end{tabular}

Table 2 Statistical Results of Patients Undergoing Central Pars Plana Vitrectomy + Phacoemulsification + IOL Implant

\begin{tabular}{|l|c|c|}
\hline Follow-Up & Mean \pm SD & *P-Value \\
\hline BCVA pre & $0.8 \pm 0.6$ & $<0.001$ \\
BCVA I month & $0.5 \pm 0.6$ & $<0.001$ \\
BCVA 6 months & $0.3 \pm 0.3$ & $<0.001$ \\
BCVA 9 months & $0.1 \pm 0.1$ & $<0.001$ \\
BCVA I year & $0.05 \pm 0.1$ & $<0.001$ \\
IOP pre & $22.09 \pm 2.4$ & $<0.001$ \\
IOP I day & $14.55 \pm 2.9$ & $<0.001$ \\
IOP I month & $12.94 \pm 2.04$ & $<0.001$ \\
IOP 6 months & $12.01 \pm 1.2$ & $<0.001$ \\
IOP 9 months & $12.20 \pm 1.9$ & $<0.001$ \\
IOP I year & $11.34 \pm 1.13$ & $<0.001$ \\
\hline
\end{tabular}

Note: $* P_{\text {-value }}<0.001$.

(Table 2 and Figure 3). Comparing the mean preoperative IOP and 1-year postoperative IOP, the difference was statistically significant at all follow-up intervals $(P<0.001)$. There was a $48 \%$ reduction in the IOP at 1-year follow-up.

\section{Discussion}

Operating on an eye with a narrow $\mathrm{AC}$ can be very complicated and stressful for the ophthalmic surgeon. A thorough preoperative assessment and planning of the surgical strategies are fundamental to minimize the complications and to achieve better visual results. ${ }^{7}$ The surgeon will face operative complications at almost every step. Efforts are made to solve this issue by many methods, such as injecting a viscoelastic substance, the use of AC maintainer, vitreous tapping, or limited vitrectomy. ${ }^{12,13}$

In this study, central pars plana vitrectomy was carried out in all patients during the course of phacoemulsification and IOL implantation. In this procedure, a small amount of vitreous humor (approximately $0.2 \mathrm{~mL}$ ) is aspirated using an automated vitrectomy handpiece without infusion. A high vitrectomy $(2000 \mathrm{cfm})$ cutting rate with a low vacuum $(150 \mathrm{mmHg})$ setting is used for approximately 10 seconds. ${ }^{12,13}$ The surgeon must ensure that the vitrector tip is pointing down, so as not to touch the posterior capsule and to minimize the risk of hitting the retina. ${ }^{14,15}$

There was only one complication in this study, a rupture of the posterior capsule, which was resolved at the time. This may have been due to the presence of a white cataract that the vitrector did not visualize, and the minimal experience of the surgeon in the early cases. Some surgeons carry out central posterior vitrectomy twice before declaring the failure of the procedure. ${ }^{8}$ However, this complication appears more often in patients with nanophthalmia and microphthalmia, ${ }^{2}$ who were not included in this study.

Kuriakose et al ${ }^{14}$ described a minimally invasive technique in 12 eyes, involving passing a $30 \mathrm{G}$ needle through the pars plana to aspirate misdirected fluid from the vitreous cavity, either as prophylaxis just before surgery or during surgery. This method was effective in patients with angle-closure glaucoma, malignant glaucoma, and a sudden increase in vitreous pressure during surgery.

Chang, in 2001, was the pioneer in describing a singleport-limited pars plana vitrectomy without an infusion cannula, using a 20-gauge vitrectomy probe inserted through a sclerotomy incision $3.5 \mathrm{~mm}$ from the limbus, for the management of crowded eyes in phacoemulsification. ${ }^{8}$ Small-gauge vitrectomy was used for crowded eyes in later studies. ${ }^{7,8,13}$

Then, Steijns et $a{ }^{2},{ }^{2}$ in a study on four cases with a crowded eye, recommend a pars plana vitreous tap using a vitrectomy probe without irrigation, which sufficiently expanded the AC with viscoelastic injection. This allowed bimanual pupil stretching, a capsulorhexis, uneventful phacoemulsification, and foldable IOL implantation.

Chalam et $\mathrm{al}^{7}$ also suggested the use of a limited transconjunctival pars plana vitrectomy $(0.2-0.3 \mathrm{~mL})$ with a 25 


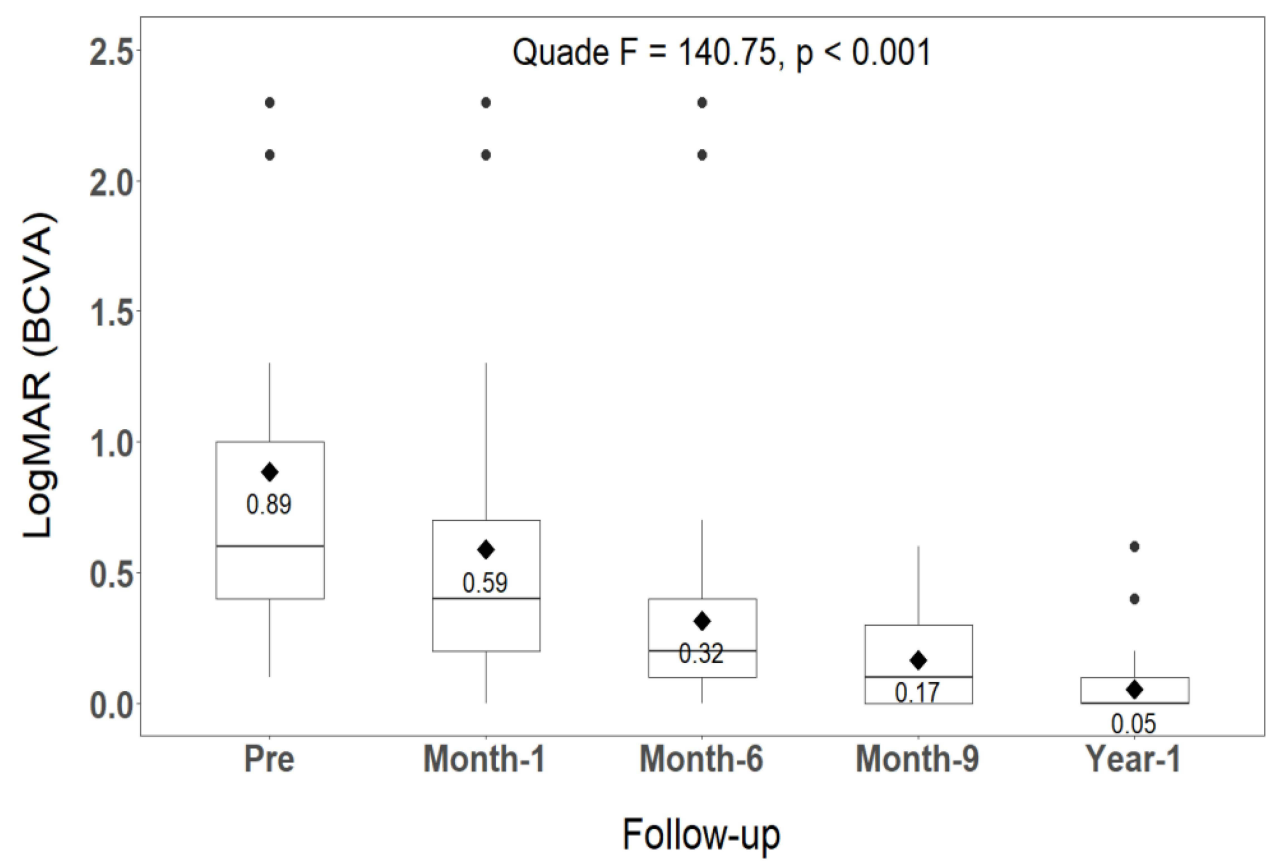

Figure 2 Preoperative visual results preoperatively and at I month, 6 months, 9 months, and I year postoperatively.

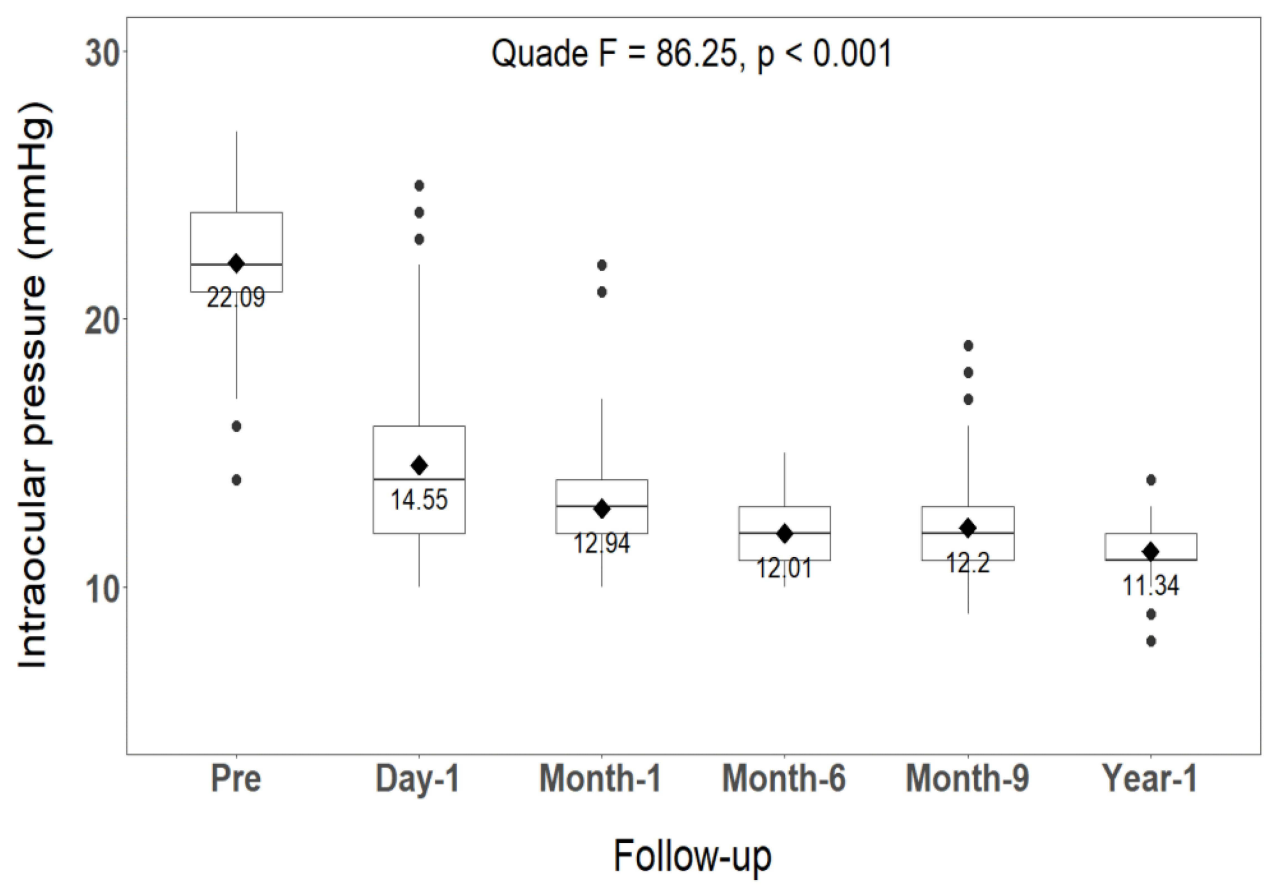

Figure 3 Reduction of preoperative intraocular pressure at I year after central pars plana vitrectomy + phacoemulsification + intraocular lens.

G high-speed cutter during the phacoemulsification procedure in eyes with very shallow AC due to increased posterior vitreous pressure. This technique facilitated all operational steps by inducing deepening of the AC, with fewer complications like posterior capsule rupture and malignant glaucoma (aqueous misdirection).
Miura et $\mathrm{al},{ }^{5}$ in their study on 17 eyes with angleclosure glaucoma, proved that performing phacoemulsification and IOL implantation associated with limited 25 $\mathrm{G}$ sutureless vitrectomy resulted in a well-formed $\mathrm{AC}$ with significant reduction in the IOP on the first postoperative day. 
Dada et $\mathrm{al}^{9}$ recommend the use of a sutureless, smallgauge, pars plana partial-core vitrectomy as an effective technique to overcome these problems. The controlled debulking of the anterior vitreous leads to posterior displacement of the lens, deepening the AC and thus facilitating surgical manipulations within the chamber. The IOP is also lowered, decreasing the positive vitreous pressure and the chances of posterior capsule rupture, iris prolapse, and suprachoroidal hemorrhage. Thus, a controlled capsulorhexis and uneventful phacoemulsification are possible, with decreased risk of damaging the corneal endothelium.

In this study, our patients had axial length less than $22.0 \mathrm{~mm}$ and AC depth less than $2.0 \mathrm{~mm}$. Comparing the mean preoperative IOP and 1-year postoperative IOP, the difference was statistically significant at all follow-up intervals $(P<0.001)$. We found a $48 \%$ reduction in the IOP, and visual acuity remained stable at 1 year of followup $(P<0.001)$. All cases were managed with central pars plana vitrectomy + phacoemulsification + IOL implantation. We did not need to perform a second surgery after 1 year of follow-up. Complications related to the process, such as vitreous hemorrhage, retinal tear, and detachment, and other complications such as corneal decompensation, were not observed in any case. ${ }^{15-17}$ There was only one complication, a rupture of the posterior capsular bag, which was quickly resolved.

\section{Conclusion}

Our findings indicate that central pars plana vitrectomy combined with cataract surgery with phacoemulsification plus IOL implantation in small eyes, with axial length less than $22.00 \mathrm{~mm}$ and with an AC depth less than $2.0 \mathrm{~mm}$, is a safe technique. This method widens the AC intraoperatively to provide a significant decrease in IOP in the postoperative period, and improves visual acuity. A low rate of complications can be achieved in experienced hands, avoiding malignant glaucoma intraoperatively. This technique can be performed on all types and grades of cataracts.

\section{Acknowledgments}

We would like to express our deepest gratitude to Clinica La Luz for allowing data collection and to the statistical analysis staff. We wish to thank the study participants for their willingness to participate. This study did not receive funding from any organization.

\section{Disclosure}

The authors report no conflicts of interest in this work.

\section{References}

1. Hoffman RS, Vasavada AR, Allen QB, et al. Cataract surgery in the small eye. J Cataract Refract Surg. 2015;41:2565-2575.

2. Steijns D, Bijlsma W, Van der Lelij A. Cataract surgery in patients with nanophthalmos. Ophthalmology. 2013;120:266-270.

3. Ho TC. Phacoemulsification and intraocular lens implantation for acute angle closure. J Cataract Refract Surg. 2006;32:1407.

4. Imaizumi M, Takaki Y, Yamashita H. Phacoemulsification and intraocular lens implantation for acute angle closure not treated or previously treated by laser iridotomy. $J$ Cataract Refract Surg. 2006;32:85-90.

5. Miura S, Leki Y, Ogino K, Tanaka Y. Primary phacoemulsification and aspiration combined with 25 -gauge single port vitrectomy for management of acute angle closure. Eur J Ophthalmol. 2008; $18: 450-452$.

6. Kuchle M, Viestenz A, Martus P, Handel A, Junemann A, Naumann GO. Anterior chamber depth and complications during cataract surgery in eyes with pseudoexfoliation syndrome. $\mathrm{Am}$ J Ophthalmol. 2000;129:281-285.

7. Chalam KV, Gupta SK, Agarwal S, Shah VA. Sutureless limited vitrectomy for positive vitreous pressure in cataract surgery. Ophthalmic Surg Lasers Imaging Retina. 2005;36:518-522.

8. Chang DF. Pars plana vitreous tap for phacoemulsification in the crowded eye. J Cataract Refract Surg. 2001;27:1911-1914.

9. Dada T, Kumar S, Gadia R, Agarwal A, Gupta V, Sihota R. Sutureless single- port transconjunctival pars plana limited vitrectomy combined with phacoemulsification for management of phacomorphic glaucoma. $J$ Cataract Refract Surg. 2007;33:951-954.

10. Wladis E, Gerwitz M, Guo S. Cataract surgery in the small adult eye. Surv Ophthalmol. 2006;51:153-161.

11. Cheon MH, Sung KR, Choi EH, et al. Effect of age on anterior chamber angle configuration in Asians determined by anterior segment optical coherence tomography; clinic- based study. Acta Ophthalmol. 2010;88:e205-e210.

12. Mackool RJ. Pars plana vitreous tap for phacoemulsification in the crowded eye. J Cataract Refract Surg. 2002;28:572-573.

13. Kaplowitz K, Yung E, Flynn R, Tsai JC. Current concepts in the treatment of vitreous block, also known as aqueous misdirection. Surv Ophthalmol. 2015;60(3):229-241. doi:10.1016/j.survophthal.20 14.12.004

14. Kuriakose T, Jasper S, Thomas S. Pars-plana fluid aspiration for positive vitreous cavity pressure in anterior segment surgeries. Ind J Ophthalmol. 2018;66:565-567.

15. Smith JM, Mathias MT, Oliver SC, Mandava N, Olson JL, Quiroz- Mercado $\mathrm{H}$. The influence of needle gauge and infection source on vitreous aspirate cultures. Br J Ophthalmol. 2006;100: 453-455.

16. Nossair A, Ewais W, Ali L. Retrospective study of vitreous tap technique using needle aspiration for management of shallow anterior chamber during phacoemulsification. J Ophthalmol. 2017;17:1-6.

17. He F, Qian Z, Lu L, et al. Clinical efficacy of modified partial pars plana vitrectomy combined with phacoemulsification for malignant glaucoma. Eye. 2016;30:1094-1100. 


\section{Publish your work in this journal}

Clinical Ophthalmology is an international, peer-reviewed journal covering all subspecialties within ophthalmology. Key topics include: Optometry; Visual science; Pharmacology and drug therapy in eye diseases; Basic Sciences; Primary and Secondary eye care; Patient Safety and Quality of Care Improvements. This journal is indexed on PubMed
Central and CAS, and is the official journal of The Society of Clinical Ophthalmology (SCO). The manuscript management system is completely online and includes a very quick and fair peer-review system, which is all easy to use. Visit http://www.dovepress.com/ testimonials.php to read real quotes from published authors. 